\title{
Rancang Bangun Sistem Absensi STMIK AUB Surakarta Berbasis NodeMcu V3 Lolin ESP8266
}

\author{
Haryanto $^{* 1}$, De ssyana Kardha ${ }^{2}$, B udhi Sumboro ${ }^{3}$, Roffi Rengga Waryatko ${ }^{4}$ \\ 1,2,4 Program Studi Sistem Komputer, STMIK AUB, Surakarta, Indonesia \\ ${ }^{3}$ Program Studi Sistem Informasi, STMIK AUB, Surakarta, Indonesia \\ e-mail: *1 haryanto@stmik-aub.ac.id, ${ }^{2}$ dessyanakardha@stmik-aub.ac.id, \\ 3budhi.sumboro@stmik-aub.ac.id, ${ }^{4}$ finggaaa@gmail.com
}

\begin{abstract}
Abstrak
Dunia perindustrian, pendidikan, perkantoran atau apapaun, sangat melekat dengan adanya absensi. Sebuah proses yang dijalankan dengan sistem yang meng hasilkan sebuah laporan absen dari instansi tersebut. STMIK AUB Surakarta adalah sebuah kampus yang tidak jauh dengan kata absensi. Dalam kegiatan belajar mengajar, dari karyawan atau dosen maupun mahasiswa memiliki peran penting dalam proses absensi tersebut. Namun, banyak yang masih tidak memperdulikan tentang kelemahan dalam sebuah sistem.

Adanya perumusan masalah tersebut, perlu diciptakan sebuah sistem baru yang dapat memberikan keefisiensian proses absensi dan mampu mengurangi tingkat kelemahan dari sistem lama dalam proses absensi tersebut. Pada penelitian ini, peneliti membuat sebuah sistem absensi elektronik yang dapat dikendalikan dengan interface web yang mampu merekap pekerjaan dengan kendali jarak jauh.

Hasil penelitian ini menggunakan NodeMCU V3 LOLIN ESP8266 sebagai kepala mikrokontroler yang berfungsi untuk mengatur dan memberikan perintah terhadap keypad dan FPM-10a sebagai alat inputnya. Adapun alat lainnya untuk membaca kode barcode yaitu barcode scanner. Kesimpulan yang didapat denganjaringan internet yang stabil diperoleh respon pengontrolan waktu sangat cepat yaitu 4/detik untuk proses penyimpanan menuju database serveryang nantinya akan disajikan didalam interface web.
\end{abstract}

Kata kunci-NodeMCUV3, FPM-10a, ESP8266, Barcode Scanner, Absensi Elektronik

Abstract
The world of industry, education, offices or whatever, is very attached to the absence. A process that is carried out with a system that produces an absent report from the agency. STMIK AUB Surakarta is a campus not far from the word absences. In teaching and learning activities, from employees or lecturers and students have an important role in the attendance process. However, many still do not care about weaknesses in a system.

The existence of the formulation of the problem, needs to be created a new system that can provide the efficiency of the attendance process and be able to reduce the level of weakness of the old system in the attendance process. In this study, researchers created an electronic attendance system that can be controlled with a web interface that is able to recap work with remote control.

The results of this study use NodeMCU V3 LOLIN ESP8266 as the head of the microcontroller which functions to regulate and give commands to the keypad and FPM-10a as input devices. The other tool for reading barcodecodes is the barcode scanner. The conclusion 
obtained with a stable internet network response time control is very fast that is 4 / second for the storage process to the database server which will be presented in the web interface.

Keywords-NodeMCUV3, FPM-10a, ESP8266, Barcode Scanner, Electronic Attendance.

\section{PENDAHULUAN}

STMIK AUB Surakarta telah menerapkan sistem absensi untuk kegiatan di kampus dalam kesehariannya. Sistem absensi ini ditujukan kepada dosen atau karyawan dan kepada mahasiswa. Namun, sistem absensi untuk mahasiswa dalam kegiatan belajar mengajar belum memanfaatkan kemajuan teknologi. Sistem absensi tersebut menggunakan buku absensi yang dibawa dosen pengampu sebelum memasuki ruangan untuk melakukan kegiatan belajar mengajar. Tingkat kemanan dari sistem absensi dengan buku absensi ini juga tergolong rendah. Banyak kasus yang terjadi ketika mahasiswa salah melihat pertemuan dan memberi paraf atau tanda tangan di buku absensi. Hal yang terjadi maka dosen harus teliti dan meneliti kembali hasil dari absen pada pertemuan tersebut. Kasus lain juga sering terjadi ketika mahasiswa salah memberikan paraf atau tanda tangan pada baris yang tidak sesuai nama dan nim nya. Selain absen mahasiswa untuk perkuliahan, adapun absensi mahasiswa untuk Ujian Tengah Semester (UTS) dan Ujian Akhir Semester (UAS) juga menggunakan buku absen untuk melakukan kegiatan absensi. Namun berbeda dengan kasus sebelumnya, pelaku utama dalam hal UTS dan UAS yaitu pengawas ujian. Pengawas ujian akan berkeliling untuk melakukan absen pada kartu absen mahasiswa. Hal ini dapat memberikan dampak negatif bagi keadaan sekitar. Sedangkan sistem absensi pada dosen dan karyawan di STMIK AUB Surakarta sudah memanfaatkan kemajuan teknologi dengan menerapkan sistem absensi berbasis Fingerprint. Sistem ini sangat membantu dalam kegiatan absensi untuk menjaga tingkat efektifitas dalam sebuah kegiatan absensi. Namun, adanya kekurangan yang masih dimiliki sistem absensi saat ini yaitu pada pihak Biro Adminidtrasi Umum (BAU) bagian kepegawaian. Adapun kekurangan ini yaitu sistem lama belum bisa merekap atau mencetak data rekap absensi dosen atau karyawan dengan tidak terpaku waktu dan tempat. Karena pada saat ini, sistem masih menggunakan satu komputer yang terhubung dengan alat fingerscanner yang dapat melakukan kegiatan merekap data absen.

Perkembangan teknologi informasi, banyak diciptakan sebuah sistem yang mampu mempermudah pekerjaan manusia. Sistem absensi elektronik ini adalah salah satu perkembangan teknologi informasi dalam bidang absensi dan rekap data. Sistem ini menggunakan fingerscanner untuk melakukan kegiatan absensi bagi dosen atau karyawan dan barcode scanner untuk melakukan kegiatan absensi bagi mahasiswa. Dalam segi data, sistem absensi elektronik ini mampu memberikan hasil rekap data untuk harian, bulanan, maupun tahunan. Rekap data ini juga mampu dilakukan tanpa harus terikat waktu dan tempat, karena sistem absensi elektronik ini sudah dibelaki web interface yang dapat diakses dimanapun dan kapanpun tanpa harus terikat waktu dan tempat.

\section{METODE PENELITIAN}

\subsection{Wawancara}

Proses metode pengumpulan data ini peneliti melakukan wawancara pada Mahasiswa tentang penggunaan absensi yang sedang berjalan saat ini. Mahasiswa tersebut bernama Dimas angkatan 2017. Peneliti menanyakan beberapa hal meliputi tata cara absensi matakuliah, absensi UTS dan absensi UAS, kelemahan dan kelebihannya. Peneliti juga melakukan wawancara kepada pihak BAU terkait dengan pelaporan absensi karyawan dan dosen dengan sistem yang sedang berjalan saat ini bersama Ibu Ganis. 


\subsection{Observasi}

Peneliti melakukan pengamatan secara langsung proses absensi dengan sistem lama di dalam kegiatan belajar mengajar, kegiatan UTS maupun kegiatan UTS. Selain kegiatan belajar mahasiswa, peneliti juga melakukan pengamatan terhadap absensi fingerprint untuk karyawan dan dosen. Selain itu, peneliti juga mengadakan pencatatan terhadap dokumen-dokumen seperti buku absensi serta cara kerja berdasarkan sistem yang sedang berjalan.

\subsection{Studi Pustaka}

Sumber data diperoleh dari jurnal yang berkaitan dengan pengembangan absensi elektronik dengan fingerprint dan data internet yang berkaitan dengan pembuatan web menggunakan PHP. Studi Pustaka digunakan sebagai referensi atau acuan yang valid mengenai data-data tersebut di buku-buku, jurnal dan internet dan data yang diperoleh berupa dasar, konsep ataupun penelitian terdahulu.

\section{HASIL DAN PEMBAHASAN}

\subsection{Pengujian Sistem}

Setelah selesai dilakukan perancangan alat dan program maka tahap selanjutnya adalah pengujian absensi elektronik yang berguna untuk mengetahui kinerja absensi elektronik yang diharapkan sesuai dengan penelitian ini.

\subsubsection{Pengujian Absensi Dosen/Karyawan}

Setelah melakukan perancangan alat NodeMCU V3 LOLIN ESP8266 dengan Fingerprint FPM-10a dan Numpad 3x4, maka peneliti melakukan pengujian untuk penyimpanan data menuju database server. Pengujian ini menggunakan serial monitor sebagai alat utama dalam proses pengujian.

Langkah selanjutnya, pastikan alat NodeMCU V3 LOLIN ESP8266 sudah mendapatkan arus yang diperlukan yaitu $5 \mathrm{v}$. Identifikasi paling mudah untuk melihat apakah rangkaian absensi NodeMCU V3 LOLIN ESP8266 mendapatkan arus yang cukup yaitu dengan lampu yang berada pada NodeMCU V3 LOLIN ESP8266 dan Fingerprint FPM-10a menyala. Rangkaian alat dapat dilihat pada Gambar 1 dan hasil input penyimpanan ke database dapat dilihat pada Gambar 2. Sedangkan proses input dapat dilihat pada Tabel 1.

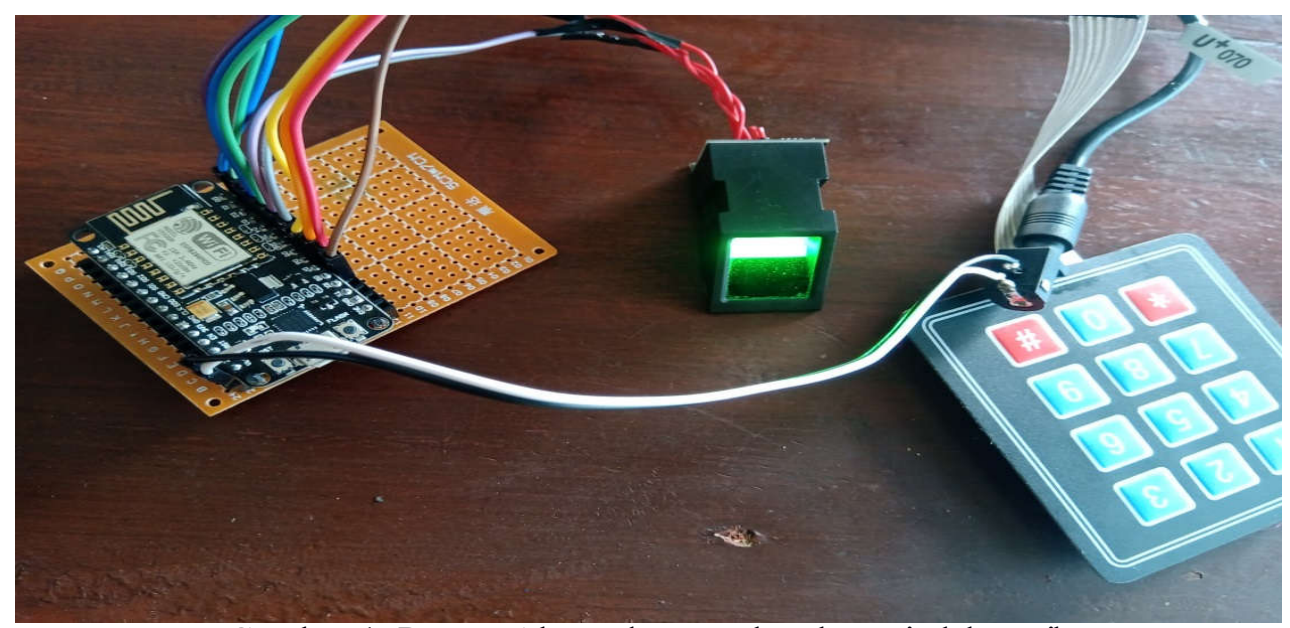

Gambar 1. Proses Absen dengan alat absensi elektronik 


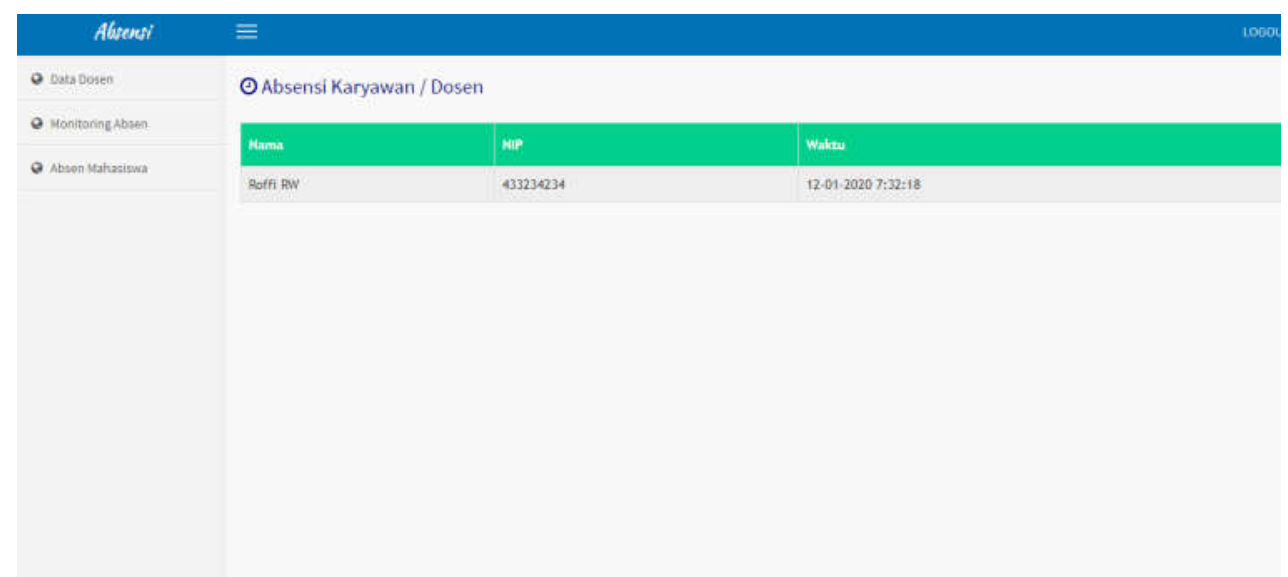

Gambar 2. Proses Monitoring Absen Dosen Sebelum data masuk

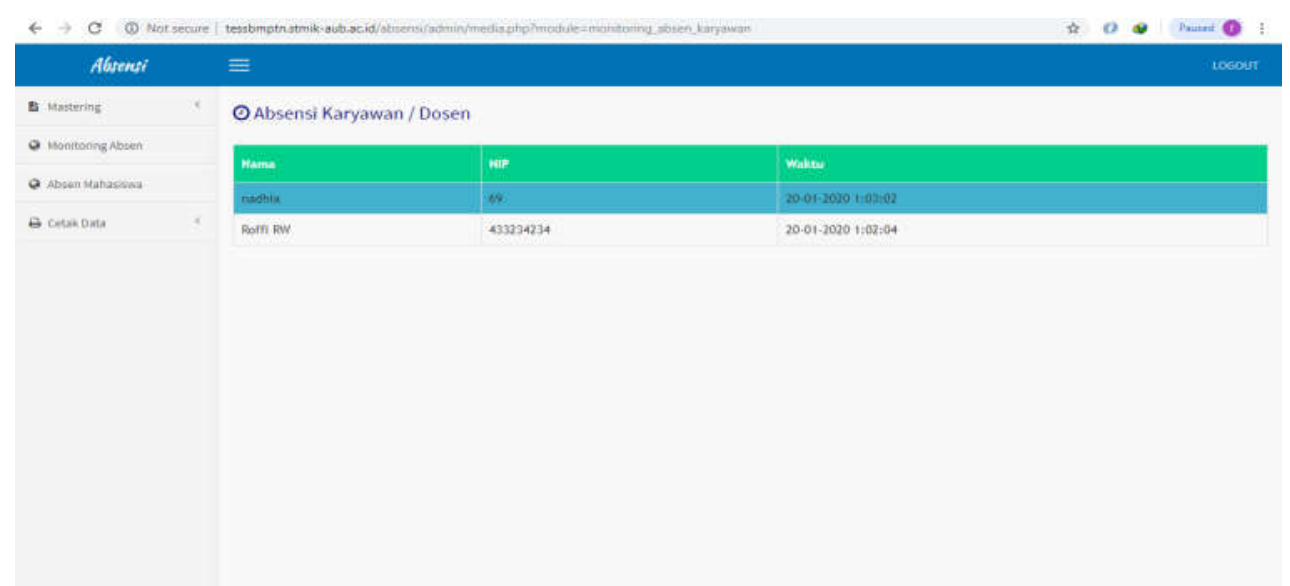

Gambar 3. Proses Monitoring Absen Dosen setelah data masuk

Tabel 1. Pengujian Sistem Absensi Dosen dan Karyawan

\begin{tabular}{|c|c|c|c|c|c|}
\hline No & Pengujian Alat & Input & Output & Delay & Ke terangan \\
\hline 1 & $\begin{array}{c}\text { Absen Dosen } \\
\text { Berangkat }\end{array}$ & 1 & $\begin{array}{c}\text { Tambah ke } \\
\text { Database }\end{array}$ & $4 /$ detik & Berhasil \\
\hline 2 & $\begin{array}{c}\text { Absen Dosen } \\
\text { Pulang }\end{array}$ & 2 & $\begin{array}{c}\text { Tambah ke } \\
\text { Database }\end{array}$ & $4 /$ detik & Berhasil \\
\hline
\end{tabular}

\subsubsection{Pengujian Registrasi Pengguna}

Proses pengujian barcode scanner bertujuan untuk mengetahui kendala dalam rancang bangun sistem absensi elektronik STIMK AUB Surakarta berbasis NodeMCU V3 LOLIN ESP8266 menggunakan web absensi untuk pengolahan datanya. Alat dapat dilihat pada Gambar 4 dan hasil input penyimpanan ke database dapat dilihat pada Gambar 5 dan 6. Sedangkan proses input dapat dilihat pada Tabel 2 . 


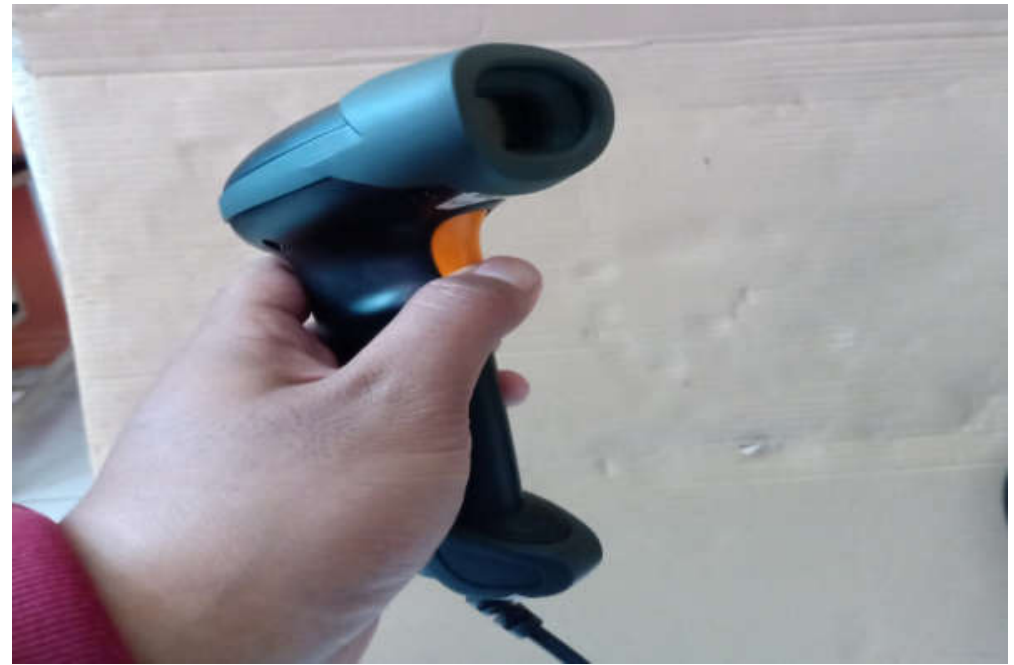

Gambar 4. Absen Mahasiswa dengan Barcode Scanner

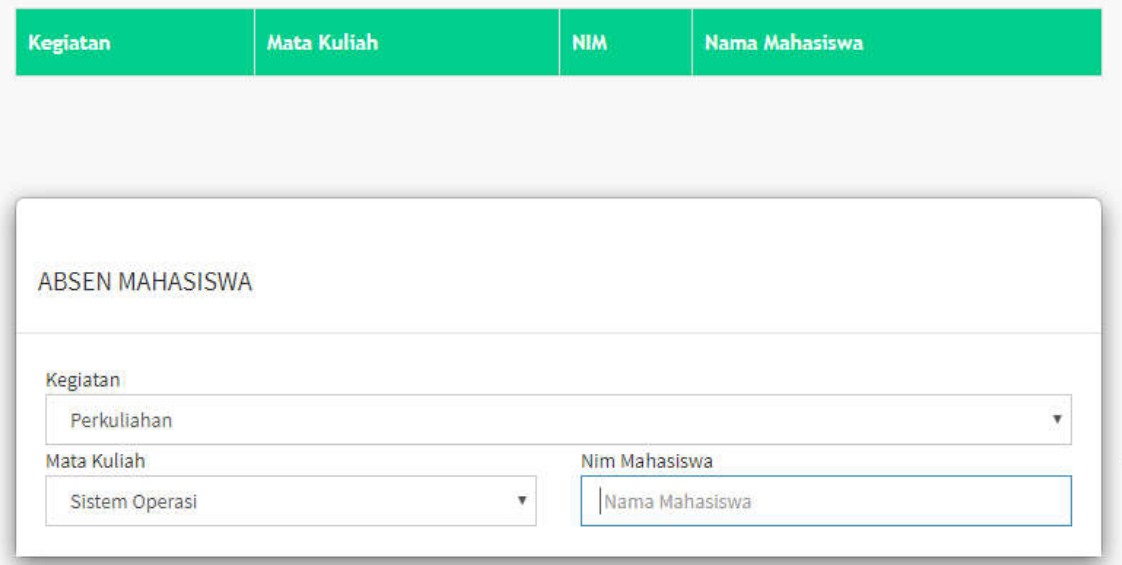

Gambar 5. Proses monitoring Absen Mahasiswa dengan Barcode Scanner sebelum data masuk

\begin{tabular}{|l|l|l|l|}
\hline Kegiatan & Mata Kuliah & NIM & Nama Mahasiswa \\
\hline Perkuliahan & Sistem Operasi & 2157200814 & Roffi Rengga Waryatko \\
\hline
\end{tabular}

ABSEN MAHASISWA

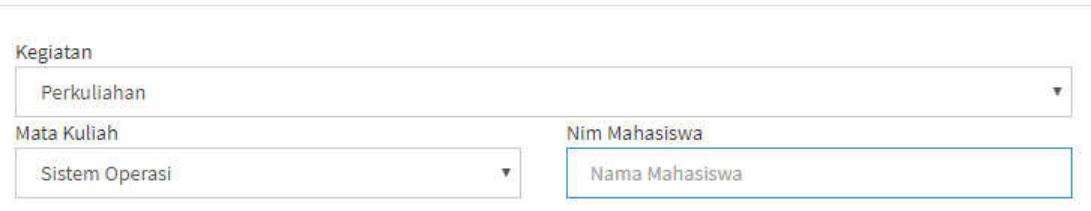

Gambar 6. Proses monitoring Absen Mahasiswa dengan Barcode Scanner setelah data masuk 
Tabel 2. Pengujian Sistem Absensi Mahasiswa

\begin{tabular}{|c|c|c|c|c|c|}
\hline No & Pengujian Alat & Input & Output & Delay & Ke terangan \\
\hline 1 & $\begin{array}{c}\text { Absen mahasiswa } \\
\text { dengan Barcode } \\
\text { Scanner }\end{array}$ & $\begin{array}{c}\text { Input NIM yang } \\
\text { kosong atau NIM } \\
\text { tidak terdaftar }\end{array}$ & $\begin{array}{c}\text { Notifikasi } \\
\text { error data } \\
\text { NIM }\end{array}$ & 0 detik & Berhasil \\
\hline 2 & $\begin{array}{c}\text { Absen mahasiswa } \\
\text { dengan Barcode } \\
\text { Scanner }\end{array}$ & $\begin{array}{c}\text { Kegiatan } \\
\text { Mata kuliah } \\
\text { NIM Mahasiswa }\end{array}$ & $\begin{array}{c}\text { Tambah ke } \\
\text { Database }\end{array}$ & $4 /$ detik & Berhasil \\
\hline
\end{tabular}

\subsection{Pembahasan}

Pada sistem absensi elektronik STMIK AUB Surakarta berbasis NodeMCU V3 Lolin ESP8266, bahasa pemrograman yang digunakan yaitu php versi 7.2, notepad++ untuk penulisan kode. FPM-10a sebagai alat fingerscanner dan PRJ-8800 sebagai alat untuk barcode scanner. apache2 sebagai web server dan mysql sebagai database management.

Alur proses sistem sistem absensi elektronik STMIK AUB Surakarta berbasis NodeMCU V3 Lolin ESP8266 yaitu, admin mendaftarkan dosen atau karyawan pada alat absensi fingerprint dengan menekan tombol 4 lalu edit data pada web dimenu data dosen.

Setelah pendaftaran, maka dosen ataupun karyawan dapat melakukan absensi dengan menekan tombol angka 1 untuk berangkat dan angka 2 untuk pulang.

Sedangkan alur proses untuk absen mahasiswa relative sama, yaitu dengan mendaftarkan mahasiswa dengan nim, nama, jurusan pada aplikasi web agar nantinya sistem dapat membaca dan scan data absen mahasiswa. Absen sendiri berada pada menu absen mahasiswa, sebelum melakukan absen, pastikan bahwa barcode scanner telah terhubung dengan komputer atau leptop yang sedang digunakan. Lalu tinggal menggunakan barcode scanner untuk membaca kode barcode yang berisi nim mahasiswa.

Jika telah melakukan absen menggunakan alat absen fingerprint maupun absen barcode scanner, data akan muncul pada menu masing masing. Data tersebut yang nantinya akan di proses untuk dijadikan cetakan sesuai dari format yang diminta.

\section{KESIMPULAN}

Rancang bangun sistem absensi STMIK AUB Surakarta berbasis NodeMCU V3 LOLIN ESP8266 yang selesai dilakukan, disimpulkan bahwa sistem absensi dosen atau karyawan berbasis NodeMCU V3 LOLIN ESP8266 berhasil dirancang dan dibangun menggunakan NodeMCU V3 sebagai platform mikrokontroler yang sudah terdapat ESP8266 berfungsi sebagai modul Wi-Fi. Keypad sebagai alat input kode dan fingerprint FPM-10a sebagai pembaca sidik jari. Sedangkan untuk absen mahasiswa berhasil dirancang dengan menggunakan barcode scanner sebagai pembaca kode barcode. Aplikasi web sebagai user interface atau antarmuka pengguna dengan menggunakan pemrograman PHP dan database MySQL berhasil dibangun dan dapat diakses seperti selayaknya mengakses web pada komputer.

Implementasi dan pengujian sesuai perancangan, rangkaian absensi elektronik berbasis NodeMCU V3 Lolin ESP-8266 yang langsung terintegrasi ke penyimpanan database berhasil dilakukan. Implementasi dan pengujian sesuai perancangan, rangkaian absensi mahasiswa dengan barcode scanner yang terintegrasi ke penyimpanan database berhasil dilakukan. Implementasi dan pengujian, hasil output cetakan rekap data absensi dosen atau karyawan dan absensi mahasiswa sesuai dengan perancangan berhasil dilakukan 


\section{SARAN}

Alat ini dapat dikembangkan lebih lanjut sehingga bisa menjadi sempurna, beberapa pengembangan yang bisa dilakukan yaitu :

1. Perlu dicoba untuk memodifikasi dengan menambah Arduino UNO agar pin dari board semakin banyak.

2. Perlu dicoba untuk menambahkan modul $L C D 16 \times 2$ untuk memberikan output perintah maupun notifikasi kesalahan.

3. Perlu diperbaiki dalam pembacaan keypad agar dapat membaca lebih dari satu digit untuk dapat memperluas fungsi dari absensi elektronik tersebut.

\section{DAFTAR PUSTAKA}

[1] Ariata C.2019. Apa Itu Apache? Pengertian Apache Serta Kelebihan dan Kekurangannya. Glosarium. Yogyakarta.

[2] Basheer K P. 2012. Fingerprint Attendance System for Classroom Needs. India Conference (INDICON), Annual IEEE. India

[3] Coupey, E. (2001). Marketing and the internet: Conceptual foundations. Prentice Hall. Upper Saddle River NJ. Belgia.

[4] Douglas Crockford.2017.Pengenalan JSON. Library of San Francisco State University. Amerika Serikat

[5] Handson W. 2019. Integrity of NodeMCU V3 LOLIN ESP-8266. E-Journal. Inggris.

[6] https://ieeexplore.ieee.org/document/6420657. (diakses tanggal 07 Januari 2020).

[7] https://www.academia.edu/37338927/A_WIRELESS_FINGERPRINT_ATTENDANC E_SYSTEM. (diakses tanggal 07 Januari 2020).

[8] https://www.olsera.com/id/blog/apa-itu-barcode-scanner-mengenal-definisi-dan-jenisjenis-barcode-scanner/41. (diakses tanggal 07 Januari 2020).

[9] Krishna Pattabiraman.2017. How To Set Up A Keypad On An Arduino. Circuit Basics ArduinoLady Ada. 2019. Adafruit Optical Fingerprint Sensor. Arduino halaman 7. Bandung.

[10] Pahmi Ritonga.2015. Pengertian Bahasa Pemrograman PHP Menurut Para Ahli dan Pakar. Belajar Digital Marketing. Bogor.

[11] Putra.2019. TOPOLOGI JARINGAN : Pengertian, Macam Macam Topologi \& Kelebihan Kekurangannya. Jakarta.

[12] Ragil, Wukil. (2010). Pedoman Sosialisai Prosedur Operasi Standar. Mitra Wacana Media. Jakarta.

[13] Rosa A.S, M. Shalahudin, M.2014. Rekayasa perangkat lunak terstruktur dan berorientasi objek. Jurnal Explora Informatika. Jakarta.

[14] Satrio Adi Nugroho. 2015. Penerapan Mikrokontroler Sebagai Sistem Kendali Perangkat Listrik Berbasis Android. Jurnal Explora Informatika, 4(2), 135-144.

[15] Strauss, Judy dan Frost, Raymond. (2012). E-Marketing edisi internasional ke 6. London: Pearson. London

[16] Luh Joni Erawati Dewi.2017.Media Pembelajaran Bahasa Pemrograman C++. Jurnal Pendidikan Teknologi dan Kejuruan Universitas Pendidikan Ganesha. Buleleng.

[17] Yolanda.2018. Apa Itu Barcode scanner? Mengenal Definisi dan Jenis-Jenis Barcode scanner. Surabaya.

[18] Yu Maw Win \& Saw Aung Nyein Oo.2019. Wireless Student Attendance System using Fingerprint Sensor. 